\title{
'N NUWE BENADERING TOT DIE STYL VAN MATTEUS
}

\author{
J Engelbrecht \\ Universiteit van Suid-Afrika
}

\begin{abstract}
This article tries to clarify the expression 'the style of Matthew'. Attention is given to what style is and why it demands attention. Then the way in which the style of Matthew is handled in literature is examined. Unfortunately very little attention has been paid to the concept in periodical literature, but some commentaries include a section on style. The shortcomings of these contributions are pointed out, the role of sources in the determination of style receives attention and lastly a suggestion is made as to a broader view with respect to style in the light of developments in the field of general stylistics.
\end{abstract}

\section{Inleidend}

Hoewel die vier Evangelies almal die verhaal van Jesus vertel, is dit vir elkeen wat hulle bestudeer of maar net enigsins noukeurig lees, duidelik dat elkeen dit op sy eie manier doen. Elke Evangelieskrywer druk as 't ware sy eie stempel daarop af. Hierdie 'eie stempel' moet met die individuele styl van die onderskeie skrywers te doen hê. Maar hoe sou 'n mens hierdie styl omskryf? Het dit te doen met die literêre styl wat deur 'n skrywer aangewend word? Of met die grammatikale styl? Of albei? En wat van aspekte soos die struktuur en komposisie van die Evangelies, en narratiewe elemente soos 'plot', karakterisering en vertellerskommentaar? Het dit alles met die styl van 'n spesifieke skrywer te doen, en indien 'n mens bevestigend sou antwoord, is jy nie dalk besig om alle kenmerke van 'n Evangelie onder die noemer 'styl' in te druk nie?

\section{Wat is styl?}

Laat ons ter aanvang kortliks twee sake aan die orde stel, naamlik wat styl is en waarom ons dit nodig ag om daaraan aandag te gee. Wat eersgenoemde betref, is dit geen maklike taak om 'n bevredigende definisie van styl te gee nie. Tufte (1971:2) 
wys daarop dat styl waarskynlik in die algemeen verwys na iemand se 'way of writing', maar dat daar onder laasgenoemde uitdrukking omtrent enigiets verstaan kan word. Sy gee verder (1971:4) 'n paar definisies wat deur andere uitgespreek is, soos die volgende: 'Le style, c'est l'homme même' (Buffon); 'Proper words in proper places make the true definition of a style' (Swift); 'Style is the ultimate morality of mind' (Whitehead); 'In stating as fully as I could how things really were, it was often very difficult and I wrote awkwardly, and the awkwardness is what they called my style' (Hemingway).

Op die gebied van die styl van Nuwe-Testamentiese skrywers sou 'n mens waarskynlik ook heelwat verskillende definisies kon kry, aangesien dit blyk dat daar nog nie indringend besin is oor die aangeleentheid nie, soos aangevoer word in die onlangse proefskrif van Botha (1989). Eerder as om self 'n definisie te probeer gee, volstaan ek met die volgende definisie van Botha (1989:59), waarmee ek myself grootliks kan vereenselwig:

Style has to do with the choices available to users of language, and since these choices are determined by specific needs and circumstances, style is a contextually determined phenomenon. Because of this, style in effect deals with the successful communication of texts in context. Every aspect of language which facilitates this process of communication, therefore, has to do with the style of the text. This, however, does not mean that a general description of all the innumerable linguistic and literary features in a text, will amount to a description of the style of a text. Far from it. Only those features which facilitate the specific communication in that specific circumstance can be considered of stylistic value in this paradigm. The features in a text which facilitate this process should not be limited, and can vary according to the specific needs of a specific text or context.

Uit hierdie definisie blyk dat die presiese beskrywing van styl 'n heel ingewikkelde saak is waaroor baie gedebatteer kan word, maar ook dat dit 'n baie meer omvattende saak is as wat normaalweg blyk uit die manier waarop daarmee omgegaan word, in elk geval op Nuwe-Testamentiese gebied.

\section{Waarom is styl belangrik?}

Wat die tweede saak hierbo betref, naamlik die funksie van 'n stylondersoek, kan Leech (1985:39) se onderskeiding ons waarskynlik van nut wees. Hy sê dat daar onderskei kan word tussen deskriptiewe (descriptive) stilistiek, waar die doel uitsluitlik is om styl te beskryf, en verduidelikende (explanatory) stilistiek, waar die doel is om stilistiek te gebruik om iets te verduidelik. Binne laasgenoemde kan weer verder onderskei word tussen die ekstrinsieke, waar die doel is om te soek na die outeur(s) of die kronologie van geskrifte, en die intrinsieke, waar die doel is om die betekenis of waarde van die teks self te verduidelik. Hoewel al hierdie soort van ondersoeke na styl legitiem kan wees, is dit veral laasgenoemde wat nuttig kan wees op die terrein van die Nuwe-Testamentiese geskrifte, en wat kan bydra tot die beter verstaan van dié geskrifte. Dit blyk egter 'n groot leemte te wees in bestaande 
literatuur, waaronder die meeste kommentare ook gereken kan word. Ten spyte van die feit dat 'n spesifieke Nuwe-Testamentiese skrywer se styl soms aandag ontvang, kry'n mens nie die indruk dat dit ingespan word om dié skrywer se geskrif beter te verstaan nie.

\section{Gebreke in die behandeling van styl}

Om oor die styl van Matteus, waarin hierdie artikel geïnteresseerd is, te praat, is dit sekerlik nodig om eers te kyk wat ander daaroor te sê het. As 'n mens egter gehoop het dat jy heelwat literatuur oor die spesifieke styl van die verskillende Evangelieskrywers gaan kry, lyk dit my, word jy in jou hoop beskaam. Vir sover ek kan vasstel is daar nie in die tydskrifliteratuur veel aandag aan die styl van Matteus gegee nie. Hier en daar 'n aspek wat onder die noemer 'styl' sou kon inpas, (vgl Schedl 1981 oor Kompositionskunst in Mt 26:6-13, Wenham 1986 oor die sintaksis van Mt 19:9, Matera 1987 oor die 'plot' van Mt, Burnett 1987 oor reader construction, Craddock 1988 oor die Evangelies as literatuur, Kingsbury 1988 oor die leser van Mt, Meyer 1988 oor konteks as draer van betekenis, ens), maar nêrens 'n verduideliking van wat gesien word as die styl van Matteus nie, ook nie 'n oorkoepelende beskrywing van sy styl nie.

Dan kan 'n mens jouself wend na die Matteuskommentare. Die afgelope dekade het juis so 'n ryke oes daarvan opgelewer. Asof daar nie al reeds baie kommentare voor die tyd was nie, het omtrent elke jaar van die tagtigerjare een of meer nuwe Matteuskommentare opgelewer (minstens vier in 1986). Maar weer eens word 'n mens teleurgestel oor die aandag wat kommentatore aan die styl van die Evangelie gee. By die meeste kom dit nie juis ter sprake nie, hier en daar is daar wel 'n poging, maar nêrens vind 'n mens iets wat werklik bevredig nie. Laat ons aandag gee aan 'n paar van die kommentare wat wel in een of ander vorm iets oor die styl van Matteus sê. Hier het ek my nie net tot die laaste tien jaar beperk nie.

Onder die ouer kommentare staan Allen, wie se kommentaar die eerste keer in 1907 verskyn het, bekend as een van die kommentatore wat 'n groot bydrae gelewer het op die gebied van taalkundige aspekte (dieselfde geld vir Lagrange [1923] en Schlatter [1933]). Allen se afdeling oor styl (vgl 1957:lxxxv-lxxxvii) is egter tipies van die problematiese stylondersoeke wat die grootste deel van Nuwe-Testamentiese kommentare kenmerk, naamlik dat hulle net aan enkele aspekte van styl aandag gee, sonder om te verduidelik waarom juis dié spesifieke aspekte en sonder dat dié besondere aspekte wat uitgelig word verder 'n besondere rol speel in die uitleg van die Evangelie. Allen maak 'n kort opmerking oor Arameïsmes wat minder in Matteus voorkom as in Markus en oor die feit dat Matteus minder deur die Septuaginta beïnvloed is as Lukas, noem nege woorde wat kenmerkend van Matteus is (teenoor Hawkins se 95) en noem dan die feit dat Matteus dikwels herhalend te werk gaan. Onder sy afdeling genaamd 'The plan and characteristics of the Gospel' (1957:|xiii-lxv) kom egter kenmerke voor wat op die styl van die Evangelie betrekking het, naamlik die groepering van stof, die rangskikking van woorde van Jesus in lang redes en die rangskikking van stof in numeriese groepe. 
'n Mens moet nie verwag om sommer in enige kommentaar se inleidende gedeelte die opskrif 'styl' raak te loop nie. Veel eerder miskien iets soos Characteristics of Schriftstellerische Eigenarten of iets dergeliks. Of hierdie characteristics altyd met styl te doen het, is 'n ander vraag. 'n Klassieke voorbeeld is dié van Hendriksen (1973:7992), wat die kenmerke van Matteus volgens die letters van die woord Matthew gerangskik het. Die kenmerke is dan:

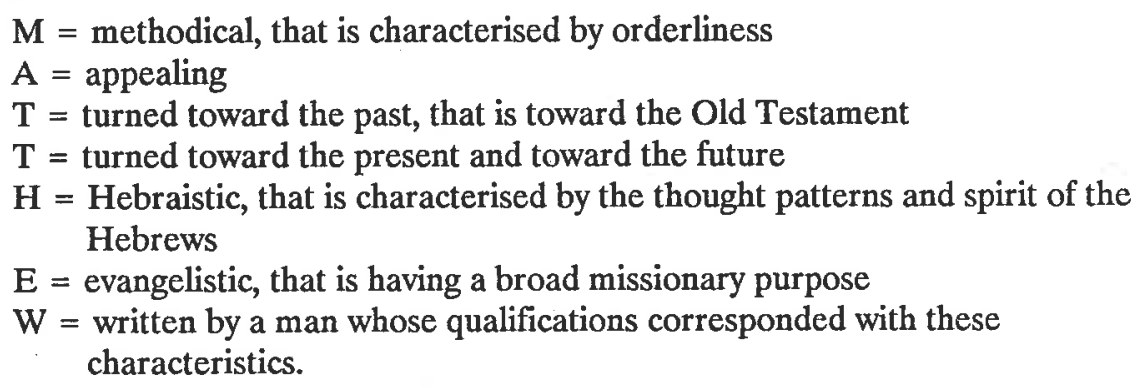

Dit is duidelik dat sommige van hierdie kenmerke met die styl van Matteus te doen het, ander weer minder. Maar dit is ook duidelik dat hier baie selektief te werk gegaan is, want Matteus het tog nog baie ander kenmerke ook, waaraan nie aandag gegee is nie.

France (1985:17-27) gee onder die opskrif 'Some characteristics of Matthew's Gospel' die volgende lys:
A. A Jewish Christian Gospel
B. a Gospel for all nations
C. a Gospel for the church
D. a carefully-constructed Gospel
E. a scripturally-based Gospel.

Weer eens het die kenmerke op een of ander manier met die styl van Matteus te doen, maar dit is onvolledig en daar word nie duidelik uitgespel waarom daar selektief te werk gegaan is nie, en of en waarom juis hierdie kenmerke kan bydra tot die beter verstaan van die Evangelie nie.

Luz (1989:49-73) is een van die weinige kommentatore wat 'n afsonderlike afdeling aan styl wy. Styl lê vir hom hoofsaaklik op grammatikale vlak. Hy gee vyf basiese kenmerke van Matteus se Grieks: dit is meer gepoleer en verhewe as die populêre Semitiese Grieks van Markus, Matteus het 'n meer verkorte en didaktiese styl as Markus, Matteus se styl is herhalend, Matteus is sterk deur die Septuaginta beïnloed, en Matteus se Grieks is deur Joodse en soms rabbynse elemente beïnvloed. Verder gee Luz dan onder die opskrif 'Styl' aandag aan sintaksis en aan Matteus se voorkeurwoorde, asook aan dié wat Matteus onwilliglik uit sy bronne oorneem.

Wat opvallend is van Luz is dat hy 'n ander afdeling in sy kommentaar het, getitel 'Structure and genre', waar hy 'n hele klompie opmerkings maak wat net so goed of miskien eerder onder styl sou kon ingepas word. Ek dink veral aan die volgende (Luz 1989:38-41): Matteus plaas soortgelyke materiaal bymekaar, daar is 'n 
ooreenkoms in die lengte van ooreenstemmende gedeeltes soos die redestof, Matteus se komposisie werk met sekere getalle-skemas, Matteus dui dikwels sy temas aan deur die herhaling van sleutelwoorde en sentrale verse, Matteus skep doeblette wat sy intensie belig, Matteus gebruik graag inclusio en chiastiese ringkomposisies en Matteus werk graag met 'sinjale' en antisipasie om die leser voor te berei vir wat later kom.

Patte (1987) se kommentaar oor Matteus het die subtitel $A$ structural commentary on Matthew's faith. In dié kommentaar maak hy 'n strukturele interpretasie van die Evangelie, op grond van 'n paar reëls wat afgelei is van Greimas se semiotiese teorie (Patte 1987:5). In hierdie interpretasie speel opposisies, en veral dan semantiese opposisies en narratiewe opposisies 'n belangrike rol. Hoewel Patte dit nie uitspel nie, het hierdie opposisies tog duidelik met die styl van Matteus te doen. Dit is verder ook deurgaans in ander kommentare duidelik dat die opmerkings wat onder die opskrif 'Struktuur' gemaak word, ten diepste met die styl van Matteus saamhang. Vir sover ek kan agterkom, word dit selde indien ooit so uitgespel, aangesien die struktuur van die Evangelie meestal as 'n afsonderlike afdeling behandel word.

Nog 'n interessante voorbeeld van hoe met styl omgegaan word, is die kommentaar van Davies en Allison (1988). Wanneer hulle die outeursvraag bespreek, wy hulle onder meer verskillende afdelings aan 'Linguistic usage and the issue of authorship' (Davies \& Allison 1988:17-21), 'Style and the issue of authorship' (1988:25-26), 'Additional Jewish features and the issue of authorship' (27-28), 'Miscellaneous considerations relating to authorship' (28-32) en 'Non-LXX text forms and the issue of authorship' (32-58). Al hierdie afdelings bevat waardevolle inligting oor die styl van Matteus, maar dit word slegs ingespan om die vraag na die outeur te belig. Daarna kom die struktuur van Matteus aan die beurt (58-72), waar daar weer eens belangrike inligting ten opsigte van die styl weergegee word. Eers dan kom 'n afdeling genaamd 'Literary characteristics' aan die beurt (72-96). Hierin kom onder meer die volgende voor:

Matteus se behandeling van Markus, voorkeurwoorde en - uitdrukkings, Semitismes, die voorliefde vir nommers, tematiese denke, herhaling, inclusio, chiasme, opskrifte en konklusies, voorafskaduwing, parallelisme, redaksionele uitbreidings en toevoegings tot die woord-tradisie en vertellerskommentaar. Hieruit blyk dat die kenmerke grootliks met die styl van Matteus te doen het, maar hierdie afdeling sou baie aangevul kon word met inligting wat weergegee is onder die verskillende afdelings oor die outeursvraag.

Laastens kan ons kortliks verwys na die kommentaar van Gundry (1982), wat hy die titel Matthew. A commentary on his literary and theological art gee. Hier, sou 'n mens verwag, gaan jy moontlik 'n bespreking oor die styl van Matteus kry. Maar sy inleidende gedeelte gaan oor kenmerke van die kommentaar, die teologie en struktuur van Matteus. In die laaste hoofstuk van sy boek bespreek hy onder meer die datering van Matteus en die outeursvraag, en in die twee afdelings, asook in die laaste gedeelte getitel 'A theological postscript', maak hy wel enkele opmerkings wat betrekking het op die styl van Matteus. Weer eens staan dit in diens van ander vrae 
en probleme en nie as 'n afdeling op sy eie wat ingespan word om die Evangelie beter te verstaan nie.

Dit wat 'n paar kommentare betref. 'n Ander boek wat 'n bespreking van die styl van onder andere Matteus gee, is dié van Turner (1976), wat as Band IV van $A$ grammar of New Testament Greek aan die styl van Nuwe-Testamentiese skrywers gewy is. Turner se bespreking is deeglik, maar soos andere voor en na hom is styl vir hom hoofsaaklik grammatikale styl. Hy bespreek dan ook sake soos Aramese invloed, Hebreeuse invloed, Semitiese invloed, sintaksis en woordeskat.

Uit hierdie kort oorsig blyk dus myns insiens dat ons op die gebied van die styl van die individuele Evangelieskrywers (in elk geval vir sover dit Matteus aangaan) nog nie veel verder gevorder het as waar ons aan die begin van die eeu met Allen se studie gestaan het nie. Dit is in ooreenstemming met die leemte wat duidelik deur Botha (1989) in sy proefskrif oor stylstudies in die Johannes-evangelie uitgewys is. In aansluiting by Botha is dit ook na my mening nodig dat daar 'n meer omvattende siening ten opsigte van styl moet kom. Dit het telkens geblyk uit die bostaande bespreking waar ek daarop gewys het dat aspekte wat onder ander opskrifte behandel is net so goed of beter onder styl sou pas. Maar oor wat presies ek onder styl sou wou sien, kom ek later terug. Eers is dit nodig om kortliks aan 'n ander vraag aandag te skenk, naamlik die vraag na bronne en die konsekwensies van die gebruik daarvan in die bespreking van styl.

\section{Die rol van bronne in stylondersoeke}

Dit is nie die regte plek om volledig op die sinoptiese probleem en die twee-bronneteorie in te gaan nie. Tog is dit nodig om dit kortliks te berde te bring. Eerstens is die vraag of Matteus oorspronklik in Grieks of Hebreeus geskryf is, miskien nog nie tot almal se bevrediging opgelos nie, maar vir my gevoel kan daar min twyfel wees dat dit Grieks was, soos telkens deur grammatikale ondersoeke bevestig is (vgl bv Turner 1976). Hiermee saam hang die vraag of Matteus die eerste Evangelie was of nie. Ten spyte van die feit dat die meeste ondersoekers vandag nie meer dink dat Matteus eerste was nie, is daar tog ook nie algemene eenstemmigheid daaroor nie. Die teorie van Matteusprioriteit het steeds en sal waarskynlik altyd sy aanhangers hê. Self deel ek nie hierdie oortuiging nie, omdat daar myns insiens te veel aspekte is wat op die twee-bronne-teorie dui, en omdat die alternatiewe vir die twee-bronneteorie, waarvan die belangrikste is dat Matteus eerste geskryf is en dat die Q-bron nie bestaan het nie, meer probleme oplewer as die twee-bronne-teorie self.

Dit beteken dus dat ek van mening is dat Matteus van Markus en die sogenaamde Q-bron gebruik gemaak het, asook ander inligting oor Jesus tot sy beskikking gehad het, wat waarskynlik eerder as losstaande mondelinge tradisies gesien kan word. Nou sou 'n mens met of sonder inagneming van hierdie toedrag van sake na die teks van Matteus kon kyk, aangesien Matteus as selfstandige teks voor ons lê. Natuurlik is dit legitiem om na Matteus alleen te kyk sonder inagneming van enige moontlike bronne. Dit kan egter verrykend wees om vergelykend na Matteus en Markus te kyk, aook vergelykend na Matteus en $Q$ vir sover ons in staat is om $Q$ te rekonstrueer 
(vgl bv die weergawe van Polag 1982). Ten opsigte van verskillende aspekte, soos Matteus se Hebreeuse en of Aramese karakter, om maar een te noem, kan dit verhelderend wees.

Wat ek dus wil sê, is dat daar by 'n ondersoek na die styl van Matteus steeds in gedagte gehou moet word dat hy van bronne gebruik gemaak het wat sy styl kon beïnloed het. Aan die ander kant moet egter nie uit die oog verloor word dat hy 'n volkome eie interpretasie van dié bronne gemaak het nie, en verder dat daar deur 'n vergelyking van Matteus met sy bronne juis tot 'n beter verstaan van die eiesoortigheid van Matteus se interpretasie gekom kan word.

\section{Gevolgtrekking en slot}

Dit bring ons by die vraag na wat 'n mens graag onder die opskrif 'Styl' sou wou sien. Eerstens is dit natuurlik heeltemal legitiem om te spesifiseer dat jy op 'n spesifieke vlak na die styl wil kyk, soos byvoorbeeld na grammatikale styl, literêre styl, komposisionele styl, teologiese styl, ensovoorts. Maar ongespesifiseerd sou 'n bespreking van styl myns insiens baie meer omvattend moet wees. Hiervoor sal 'n mens moet kennis neem van die insigte van die nuwe stilistiek wat sedert die vyftigerjare in literêre kringe in beweging gekom het (vgl Botha 1989:46vv).

Onder 'n bespreking van die styl van Matteus sou ek dus die volgende wou insluit: struktuur, komposisie, grammatikale aspekte waarby sintaktiese sowel as semantiese aspekte ingesluit is, literêre aspekte, narratiewe aspekte en aspekte rakende die lesers en resepsie van 'n teks. Sommige van hierdie aspekte is tradisioneel as deel of as geheel van stylbesprekings behandel, terwyl ander baie selde of nooit as deel van styl gesien is nie en nog ander eers in die jongste verlede aandag begin geniet het in literêre kringe, en nog glad nie of baie min in Nuwe-Testamentiese kringe.

Dit bring ons ten slotte by die vraag of hierdie siening regverdigbaar is onder een of ander teksteorie. Botha (1989:68vv) stel in sy proefskrif voor dat die speech act theory 'n bruikbare teorie is om ten opsigte van stylstudies te gebruik, en pas dit dan toe op Johannes 4:1-42. Dit wil inderdaad lyk of hierdie teorie interessante moontlikhede bied ten opsigte van stylondersoeke, en hierdie moontlikhede kan gerus verder ondersoek word. Hoewel die teorie reeds in 1955 sy beslag begin vind het met lesings deur J L Austin, is dit eers sedert die sewentigerjare ten opsigte van Bybelondersoeke begin gebruik. Dit is waarskynlik nog grootliks on(der)benut op die gebied van Nuwe-Testamentiese ondersoeke (vgl saam met ander bydraes in Semeia 41 veral die bydrae van Patte 1988). 


\section{BIBLIOGRAFIE}

Allen, W C [1907] 1957. A critical and exegetical commentary on the Gospel according to $S$. Matthew. 3rd ed. Edinburgh: Clark. (ICC).

Bellinzoni, A J 1985. The two-source hypothesis. A critical appraisal. Mason: Mercer University Press.

Botha, J E 1989. A study in Johannine style: history, theory and practice. DTh thesis, University of South Africa.

Burnett, F W 1987. Characterization in Matthew: reader construction of the disciple Peter. McKendree Pastoral Review 4, 13-43.

Craddock, F B 1988. The Gospels as literature. Encounter 49, 19-35.

Davies, W D \& Allison, D C 1988. The Gospel according to Saint Matthew. Vol 1. Edinburgh: Clark. (ICC).

France, R $\mathrm{T}$ 1985. The Gospel according to Matthew. An introduction and conmentary. Leicester: Inter-Varsity; Grand Rapids: Eerdmans. (Tyndale New Testament commentaries).

Gundry, R H 1982. Matthew. A commentary on his literary and theological art. Grand Rapids: Eerdmans.

Hendriksen, W 1973. New Testament commentary. Exposition of the Gospel according to Matthew. Grand Rapids: Baker.

Hawkins, J C [1909] 1968. Horae synopticae. Contributions to the study of the synoptic problem. 2nd ed. Oxford: Clarendon.

Kingsbury, J D 1988. Reflections on the reader of Matthew's Gospel. NTS 34, $442-$ 460.

Lagrange, M J 1923. Évangile selon Saint Matthieu. Paris: Gabala.

Leech, G N 1985. Stylistics, in Van Dijk, T A (ed), Discourse and literature. Amsterdam: John Benjamins.

Luz, U 1989. Matthew 1-7. A commentary. Transl by W C Linss. Minneapolis, Augsburg: Fortress.

Matera, F J 1987. The plot of Matthew's Gospel. CBQ 49, 233-253.

Meyer, P W 1988. Context as a bearer of meaning in Matthew. USQR 42, 69-72.

Patte, D 1987. The Gospel according to Matthew. A structural commentary on Matthew's faith. Philadelphia: Fortress.

Patte, D 1988. Speech act theory and biblical exegesis. Semeia 41, 85-102.

Polag, A 1982. Fragmenta $Q$. Textheft zur Logienquelle. Neukirchen-Vluyn: Neukirchener Verlag.

Schedl, C 1981. Die Salbung Jesu in Betanien. Zur Kompositionskunst von Mk 14:39 und Mt 26:6-13. BiLi 54, 151-162. 
Schlatter, A 1933. Der. Evangelist Matthäus. Stuttgart: Calwer.

Silva, M 1990. Language and style of the Gospels, in Skilton 1990: 27-37.

Skilton, J H (ed) 1990. The Gospels today: a guide to some recent developments. Philadelphia: Skilton House.

Tufte, V 1971. Grammar as style. New York: Holt, Rinehart and Winston.

Turner, N 1976. A grammar of New Testament Greek. Vol IV. Style, ed by J H Moulton. Edinburgh: Clark.

Wenham, G J 1986. The syntax of Matthew 19:9. JSNT 28, 17-23. 